\title{
Molecular basis for mucolytic therapy
}

\author{
BONNIE DASGUPTA MSc, MALCOLM KING PhD FCCP \\ Pulmonary Research Group, University of Alberta, Edmonton, Alberta
} B DASGuPTA, M KING. Molecular basis for mucolytic
therapy. Can Respir J 1995;2(4):223-230.

Airway mucus is a complex, viscoelastic gel that has a three-dimensional structure. It is composed of water, mucous glycoproteins, low molecular weight ions, proteins and lipids. The three-dimensional structure of the mucous gel depends on a number of forms of bonding, such as ionic bonds and disulphide bridges. Airway obstruction in cystic fibrosis (CF) lung disease is accompanied by the accumulation of thick and viscous secretions resulting from chronic infection and inflammation, promoting recurrent exacerbations. The normal, free-flowing airway mucus becomes thick and purulent in patients suffering from CF lung disease. Therefore, current approaches to the treatment of $\mathrm{CF}$ include strategies for changing the physical properties of pulmonary secretions with the goal of improving airway clearance. Some of the same strategies may be applicable in the larger group of patients with chronic obstructive airway diseases, including bronchiectasis and chronic obstructive pulmonary disease. This paper reviews various approaches to mucolysis based on the molecular nature of crosslinking and bonding in mucin gels. A brief review of the structure and biochemistry of airway mucus is followed by a discussion of the various physical and biochemical approaches to mucolysis. Seven representative mucotropic modalities are presented: N-acetylcysteine; urea; hypertonic saline; recombinant human DNase; gelsolin; oscillation; and surfactants. Each of these mucotropic modalities acts on a different component within the mucous gel. Finally, the possibilities of mucolytic synergism among these various agents are considered.

Key Words: Acetylcysteine, Airway obstruction, Cystic fibrosix. Gelsolin, Mucolysis, Recombinant human DNase. Urea

\section{Bases moléculaires en faveur d'une thérapie mucolytique}

RESUMÉ : Le mucus bronchique est un gel visco-élastique complexe possédant une structure tridimensionnelle. II se compose d'eau, de glycoprotéines muqueuses, d'ions de faible poids moléculaire, de protéines et de lipides. La structure tridimensionnelle du gel muqueux repose sur plusieurs formes de liaisons telles que les liaisons ioniques et les ponts disulfures. L'obstruction bronchique dans le cas de la fibrose kystique du pancréas (FKP) s'accompagne d'une accumulation de sécrétions épaisses et visqueuses résultant de l'infection chronique et de l'inflammation et qui favorise des exacerbations récurrentes. Le mucus bronchique, qui normalement circule librement, devient alors épais et purulent chez les patients souffrant de FKP. Donc, les approches courantes envers le traitement de la FKP comprennent des stratégies pour changer les propriétés physiques des sécrétions pulmonaires dans le but d'améliorer la clairance bronchique. Certaines stratégies peuvent être applicables au groupe de patients plus large souffrant de maladies obstructives chroniques des voies aériennes, notamment de bronchectasies et de maladies pulmonaires obstructives chroniques. Cet article examine les différentes approches envers lit mucolyse basées sur la nature moléculaire de la réticulation et des liaisons des gels des mucines. Une revue brève de la structure et de la biochimie du mucus bronchique est suivie d'une discussion. sur les différentes approches biochimiques et physiques envers li: mucolyse. Sept modalités mucotropes représentatives sont présentées : la N-acétyl-cystéine, l'urée, la solution saline hypertonique, la Dnase humaine recombinante, le gelsolin, I'oscillation et les surfactants. Chacune de ces modalités mucotropes agissent sur url composant différent du gel muqueux. Enfin, les possibilités d'unc synergie mucolytique entre ces différents agents sont envisagées.

Correspondence and reprints: Dr Malcolm King, Pulmonary Research Group, 17.3 Heritage Medical Research Centre, University of Alberta, Edmonton, Alberta T6G 2S2. Telephone 403-492-6703,Fax 403-492-4878, e-mail king@gpu.sri.ualberta.ca 
A IRWAY MUCUS IS THE FIRST LINE OF PROTECTION IN THE lungs. It traps inhaled dust particles and bacteriat and removes them from the airwaty by ciliary clearance or by coughing. Airway mucus is a complex viscoclastic gel, composed mainly of water ( 90 to $95 \%$ ) and mucins (or mucous glycoprotcins) ( $1102 \%$ ). Under nomal conditions, less than I\% of airway mucus is composed of proteins. lipids and low molecular weight ions. In patients suffering from cystic tibrosis (CF), 3 to $4 \%$ of arway mucus is composed of the lattler ( 1 ).

The viscoelastic properties of airway mucus can be attributed predominantly to its mucin content (2). Mucins are glycoproteins composed of a polypeptide core, rich in serine. threonine and proline, with numerous oligosatcharide side chatins connected to the core through O-glycosidic linkages via $\mathrm{N}$-acetylgalactosamine (3). Mucins are polydisperse, with a large size (3 to $7 \mathrm{MDa}$ ) and an unusual molecular structure that distinguishes them from other components of mucus, as well as from most other glycoproteins. Airway mucins are synthesized and secreted by a number of specialized cells (ie, nucous and serous cells of the submucosal glands, and goblet and Clara cells of the surface epithelium).

\section{SOL AND GEL PHASES OF MUCUS}

The airways of the respiratory tract are lined with a double lityer of fluid, a superficial gel layer and an underlying sol layer. The gel layer is produced from the mucous glands and the goblet cells in the airways.

The notion of the mucous bilayer (gel and sol phases) makes it simple to understand mucus transport, especially the velocity of transport that is related to the frequency of beat and length of cilia. In 1961. Hilding (4) demonstrated the optimal rate of mucociliary clearance in animals to be about $15 \mathrm{~mm} / \mathrm{min}$. It was explaince that this velocity is due to the gel layer, which interacts with the ciliary tips during the effective phasse of the beat and perhaps during the peak velocity of that phase. During the recovery phase, the cilia interact only with the sol latyer, and each cilium is slightly ahcad in the phase of the cycle from the onc immediately behind it. In other words, Hilding demonstrated the reverse direction taken by the waves of the rccovery stroke in the gel phase. However, Sanderson and Sleigh (5) suggested that the sol layer shows little net movement.

\section{CROSSLINKS IN THE MUCOUS GEL LAYER}

The highly viscoelastic airway mucus secretions exhibil characteristics of a gel. A gel is described as a solution in which the macromolecules are all linhed together by at lealst onc crosslink per chain to procluce very large macroscopic aggregates (6). The molecular nature of crosslinking of airway mucus depends on a number of different types of bonds. Therefore, to reduce the viscosity and clasticity of the purulent mucus, the crosslinking and bonding within the mucous gel must be broken.

A normal mucous gel is composed of numerous bonds (Figure 1), including covalent bonds (such as disulphide bonds), hydrogen bonds (which bind hydroxyl groups), ionic

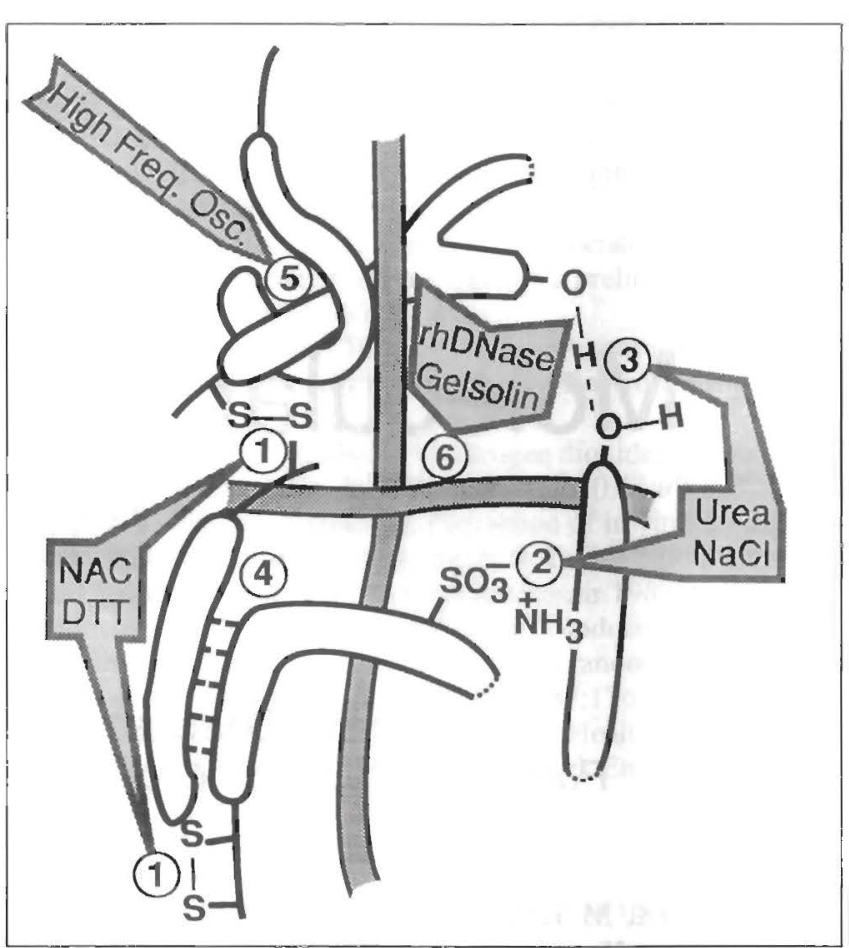

Figure 1) Diagram illustrating the types of bonding in a mucous gel (each subject to mucolysis), and site of action of various mucolytic treatments. I. Covalent bonds (primarily disulphide bonds, both intra- and intermolecular): 2. Ionic bonds (mucin macromolecules with both positive and negative fixed charges capable of interacting); 3. Hydrogen bonds (due to the oligosaccharide sidechains). 4. van der Waals' forces (with possible importance of interdigitation between oligosaccharide molecules); 5. Intermingling (physical entanglements); 6. Extracellular DNA and F-actin (parallel network formation in infection). DTT Dithiothreitol; NAC N-acetylcysteine: rhDNase Recombinant human DNase

bonds (which bind sulphated sugar units to amino groups, inter alia), van der Waals' forces (weak, attractive forces that contribute to interdigitation between neighbouring molccules) and physical entanglements (mechanical entrapment between polypeptide chains) (7). In short, all of these bonds contribute to crosslinkages within the mucous gel and all are subject to mucolysis. In normal, noninfected mucus, the maljority of the bonding is due to mucins (mucous glycoproteins). Additional factors related to crosslinking within the mucous gel modify the physical properties of the gel: high water content lowers viscosity (8) while the addition of DNA (9) or serum albumin (10) raises it. In mucus produced by chronic irritation, such as smoking or sulphur dioxide exposure, the mucin macromolecules within the mucous gel develop an excess of fixed negative charges, as indicated by the histochemical shift to acidic mucin (11). This excess of negative charges develops a net repulsion, making the nucous gel highly acidic.

In chronic airway infection, such as in CF airways infected by Pseudomonas species, in addition to the mucin macromolecules, the mucous gel contains DNA and F-actin (both of which are released from dying cells and bacteria), and bacterial alginate. These affix additional crosslinkages to 
TABLE 1

Approaches to mucolysis

\begin{tabular}{|c|c|c|c|c|c|c|c|}
\hline \multirow[b]{2}{*}{ Mucotropic agents } & \multicolumn{7}{|c|}{ Sources of bonding } \\
\hline & DNA & F-actin & $\begin{array}{l}\text { Disulphide } \\
\text { bonds }\end{array}$ & Ionic bonds & $\begin{array}{l}\text { Hydrogen } \\
\text { bonds }\end{array}$ & $\begin{array}{l}\text { Suface } \\
\text { tension }\end{array}$ & $\begin{array}{c}\text { Physical } \\
\text { entanglement }\end{array}$ \\
\hline rhDNase & $x$ & $?$ & & & & & $x$ \\
\hline $\mathrm{N}$-acetyicysteine & & & $x$ & & & & $x$ \\
\hline Hypertonic saline & & & & $x$ & & & $x$ \\
\hline Urea & $x$ & & & $x$ & $x$ & & $x$ \\
\hline Oscillation & $?$ & $?$ & ? & & & & $x$ \\
\hline
\end{tabular}

X Expected interaction: ? Possible interaction; bLES Bovine surfactant; rhDNase Recombinant human DNase. Exosurt (Burroughs Wellcome)

the gel network. The DNA from the host leukocytes has a very high molecular weight and is relatively inflexible, thereby forming a rigid network. In CF, DNA concentrations may even be sufficient to make the parallel DNA network stronger than the mucin matrix.

\section{MUCUS RHEOLOGY}

Mucus can be considered as a viscoelastic fluid, since it exhibits both liquid-like (viscous) and solid-like (elastic) properties. Viscosity is the resistance to flow and represents the capacity of a material to absorb energy as it moves. Elasticity is the capacity of a material to store energy used to move or deform it. The relative proportions of elasticity and viscosity are as important in describing how a material such as mucus behaves when it is subjected to external lorces as are the absolute values of either parameter (12).

The effects of different approaches to mucolysis can be tested by measuring the different physical properties of airway mucus. Viscosity and elasticity, the basic properties describing the liquid-like and solid-like properties of the mucous gel, can be measured by means of a magnetic microtheometer. Spinnability, the capacity of mucus to form threads under distraction, correlates with mucus viscoelasticily and clearability. Spinnability is measured by a filancemeter. Surfare propertices are important in determining how mucus adheres to epithelial lining and how it interacts with airflow. Mucociliary and cough clearability, the effect on clearance of airway mucus by the two major relevant mechinisms, are measured to determine ciliary action and airflow.

\section{GENERAL APPROACHES TO MUCOLYSIS AND MUCOKINESIS}

To change the physical properties of the viscous and rigid mucous gel, the direct strategy is mucolysis, but two indirect strategies may also be involved, namely secretory inhibition and mucokinesis. Mucolysis refers to the disruption of the mucous gel, generally by altering the degree of crosslinking or the interactions between the macromolecules that form the gel. Normally it is desirable to reduce the crosslinking and viscoelasticity in the mucous gel to improve clearance. Occasionally, the mucus is too thin for effective transport $(13,14)$; hence, increasing the crosstinking of the mucus by a muco- spissic agent could be appropriale. Mucolylics and mucospissics are known collectively as mucolropic agents.

The second strategy is mucokinesis, where the objective is to move the mucus physically from smaller to larger airways, from where it can be eliminated by cough clearance. Mucokinesis does not necessarily imply mucolysis, especially if the mucokinesis occurs primarily through stimulation of the cilia, or through airflow or gravily mechanisms (the Iwo primary mechanisms used to move mucus). However, agents that alter ciliary beating often also alter mucus rheology. For instance, physiotherapy methods, such as high frequency chest compression (HFCC), involve airflow regimens that have the potential to alter mucus rheology and to stimulate clearance (15).

\section{MUCOTROPIC AGENTS}

The aforementioned are general approaches 10 mucolysis. To attain the optimal effects of mucolysis, it is essential to look at the complex mucous gel. Breakage or reduction of the bonds within the mucous gel can be achieved through disruplion of the gel network, the process known as mucolysis. Mucolysis can be achieved either through physical intervention, such as high-frequency oscillation ( 6 ), or by biochemical or pharmacological agents (mucotropic agents), such as recombinant human DNase (rhDNase) or $\mathrm{N}$-acetylcysteine (NAC). Thus, by breaking the bonds, mucolysis reduces the viscoclasticity of the mucous gel. If this process is carricd out to the proper extent, it will enable the paticnt to improve mucus clearance (12).

The array of mucotropic agents described below are primary agents that either directly affect the production of mucus or change the characteristics of the mucus. There are many different types of primary mucotropic agents. Seven representaltive examples are examined here: NAC, urea, hypertonic saline, rhDNase, gelsolin, mechanical oscillation and surfactants. Each of these mucotropic modalities are meant to disrupt or modify a separate bond within the mucous gel (Table I).

\section{$\mathrm{N}$-acetylcysteine}

NAC is a derivalive of cysteine and is a thiol reducing agent. NAC has been widely used as a mucolytic agent in many countries, although not in Canada or the United States. 
It has been reported to reduce the viscosity of purulent sputum in both CF and chronic bronchitis patients (17), thus enhancing the removal of pulmonary secretions by ciliary action or cough.

The chemical structure of disulphide-containing proteins and peptides connected by disulphide linkages is altered by thiol compounds. Physical changes in the bronchial glycoprotein are the result of thiol reduction; they are associated with reduction in molecular size, sedimentation coefficient and viscosity (18). NAC reduces the disulphide bond $(\mathrm{S}-\mathrm{S})$ to a sulfhydryl bond (-SH), which no longer participates in crosslinking, thus reducing the elasticity and viscosity of mucus (19). Previous studies have shown a correlation between the reduction in mucous viscosity and the reduction of disulphide bonds (20). These mucolytic properties of NAC were tested and confirmed (by using a magnetic microrheometer) in in vitro experiments (21), where treatment with NAC resulted a reduction in the elastic shear modulus of canine tracheal mucus.

In vitro studies of the effect of NAC on the viscosity of sputum report a dose-related activity: the greater the concentration of NAC administered the greater the decrease in viscosity $(20,22)$. In terms of purulent and nonpurulent sputum, NAC demonstrated similar effects on both types of sputum. Other in vitro studies reported increasing mucolytic activity of NAC in solutions over the $\mathrm{pH}$ range of 5.5 to 8.0 (23).

Nevertheless, NAC has disadvantages, particularly in topical or aerosol administration. It is difficult for the drug to reach more peripheral airways or poorly ventilated areas in therapeutic concentrations; there is also the risk of bronchospasm in hyperreactive patients. On the other hand, NAC can be too potent in its action - it can overliquify the mucus in central airways yet underliquify the mucus in the periphery, both instances leading to suboptimal clearance (12).

\section{Urea}

Urea has long been recognized as a dissociating solvent that can break ionic and hydrogen bonds (24). In mucin gels, urea disrupts the hydrogen bonds that provide links between the oligosaccharide side chains of the neighbouring mucus molecules. The disruption of these bonds consequently reduces the physical entanglements between macromolecules, thereby reducing the viscosity of the mucus. Urea may also reduce the interaction between DNA molecules, thus further decreasing the degree of physical entanglement.

In 1966, Waldron-Edward and Skoryna (25) carried out an in vitro experiment using urea as a mucotropic agent. They reported that urea was effective only at $3 \mathrm{M}$ concentration. Concentrations less than $3 \mathrm{M}$ had no significant mucolytic effect, while concentrations higher than $3 \mathrm{M}$ overliquified purulent sputum $(26,27)$. For effective mucolysis, $0.2 \mathrm{~g}$ of urea/mL of sputum was used, although this is an immense amount of urea for nebulization. In 1974, Marriott and Richards (28) confirmed Waldron-Edward and Skoryna's findings, explaining that when administered in vitro, the mucolytic action of urea increases as its concentration in- creases from 5 to $8 \mathrm{~mol} / \mathrm{L}$. Because significant effects result only at such high concentrations, urea would not be considered appropriate for human use. However, since toxic effects are generally concentration-dependent, urea toxicity might be minimized by combining it with another mucotropic agent.

\section{Hypertonic saline}

As suggested by Figure 1, hypertonic saline breaks up the ionic bonds within the mucin gel, thereby reducing the effective degree of crosslinking and lowering the viscosity and elasticity (29). Hypertonic saline is also believed to promote mucus clearance by extracting fluid from the respiratory tract epithelium, thereby increasing the volume and water content of mucus (30). Upon administration of hypertonic saline by means of a nebulizer, water from the tissues is shifted across the epithelial membrane to dilute the saline. The diluted fluid is then eliminated from the respiratory tree by the mucociliary escalator or by coughing. Administering excessive quantities of hypertonic saline to the patient must be avoided, because it could result in hypernatremia, particularly in patients with renal insufficiency or impaired salt secretion (29).

In infected mucus, hypertonic saline separates the DNA molecules from the mucoprotein, making the mucoprotein susceptible to proteolytic enzyme digestion (31). Lieberman (32) reported that DNA cleavage by hypertonic saline increased as the ionic strength of the solution increased beyond 0.15 M. In 1978, Pavia et al (33) investigated the effect of hypertonic saline on chronic bronchitis patients. They found that, compared with normal saline, hypertonic saline $(1.21 \mathrm{M})$ doubled the rate of mucociliary clearance with an increase in the weight of sputum expectorated. Wanner $(34,35)$ noted that this stimulation of mucociliary transport by saline solutions occurs in both normal individuals and chronic bronchitis patients. Recently, hypertonic saline has been reported to enhance the removal of lung secretions in patients with CF $(36,37)$.

\section{Recombinant human DNase I}

High concentrations of DNA (up to $15 \mathrm{mg} / \mathrm{mL}$ ) have been shown to be the leading cause of the tenacious and viscous nature of the sputum $(9,38,39)$. By cleaving the DNA molecules, rhDNase reduces sputum viscosity (38) transforming the tenacious sputum from a nonflowing gel to a flowing liquid within minutes. This change in the physical property of the sputum (nonflowing gel to a flowing liquid) helps patients to remove sputum from their lungs, thereby improving lung function. This reduction in viscosity of sputum is associated with a decrease in the size of the DNA molecules within the sputum (38). In theory, rhDNase reduces only the excess viscoelasticity, leaving the glycoprotein gel intact (quasi normal). Hence, it is believed not to overliquify mucus, although this could happen in some circumstances (40).

Recent multicentre studies of exacerbations in CF patients reported that short and long term administration of rhDNase correlated with an improvement in pulmonary function $(41,42)$. The use of rhDNase (Pulmozyme, Genentech) for 
the treatment of CF patients has been approved by Health and Welfare Canada and by the Food and Drug Administration in the United States. The application of rhDNase in non-CF patients is under investigation $(43,44)$.

\section{Gelsolin}

F-actin is released from disintegrating inflammatory cells. It constitutes $10 \%$ of the total leukocyte protein (45) and develops long, protease-resistant, eminently viscoelastic filaments (46). Plasma gelsolin, a natural component of extracellular fluids, reduces the length of F-actin filaments (47). However, with the overwhelming degree of infection in $\mathrm{CF}$ airway disease, there maly be insufficient levels of natural gelsolin in the inflamed airways of the CF patient, analogous to the smail amounts of DNase also present in their airways (47). Thus, this provides the rationale for administering exogenous gelsolin or DNase in this disease.

Accumulation of the long F-actin filaments can cause mucus to be quite purulent and viscous, similar to the excess concentration of DNA networks. Vasconcellos et al (47) reported a 58\% decrease in the elastic shear modulus (the rate of reformation after distortion of the mucous gel) of $\mathrm{CF}$ sputum after treatment with gelsolin. Another study reported a significant decrease in the viscoelasticity index $\left(G^{*}\right.$, the complex shear modulus) and cough clearability index after treatment with gelsolin (48). Recently, in an in vitro study, we demonstrated that combined treatment with rhDNase and gelsolin was more effective in reducing the viscoelasticity of CF sputum than individual treatments with cither agent, indicating mucolytic synergism between the two (49). A likely explanation for this action of gelsolin is that after disassociation, gelsolin obstructs the monomers from adding back onto filaments. These results substantiate reports of mucolytic action of gelsolin and confirm its efficacy in reducing the length of F-actin filaments. This shortening of F-actin filiaments not only reduces the viscoelasticity and increases the cough clearability of mucus, but also reduces the rate of formation of the distorted mucous gel. Further work is needed in this arca because clinical studies with gelsolin have not yet been carried out.

\section{Oscillation}

As illustrated in Table 1, high frequency oscillations break up the physical entanglements by reducing the crosslinkages within the mucous gel. This disruption and disentanglement of the mucous macromolecules reduces the crosslinkages that bind the mucous glycoproteins, and thereby loosens the mucus to facilitate mucociliary clearance. However, oscillations may also break up the DNA molecules because these molecules have an inflexible helical structure, which make them more vulnerable to be broken by high frequency oscillation. Oscillation is most probably unable to break hydrogen and ionic bonds because both types of bonds are reversible and, even if broken, they will reform.

Earlier studies reported that the rate of mucociliary clearance depends on the degree of crosslinking (12); however, a large reduction in crosslinkages makes the mucus too fluid, thereby obstructing mucociliary clearance. High frequency oscillation transmits airflows through the lung tissue, vibrating the chest wall, and physically disrupting and disentangling the mucous macromolecules. High frequency oscillations could also enhance ciliary beating (15).

Our own studies indicate that oscillating CF sputum (16) results in a decrease in spinnability. This decrease in spinnability may be explained by the reduction of polymer size, induced through lysis of macromolecular backbone linkages (Figure 1). The decrease in spinnability of CF sputum correlated in previous studies (50) with increased transporlibility of mucus by ciliary and/or cough mechanisms. These changes in the physical properties of the sputum may therefore be considered potentially beneficial in the treatment of CF patients.

The clinical value of HFCC is due to the high frequency airflow it generates through the lungs. This airflow not only reduces the viscosity of sputum but it also provides significant oscillatory airflow at the mouth through mucus-airflow interaction, consecuently provoking the patient to cough and expectorate a significant amount of sputum. Hence, the high frequency airflows are partially analogous to cough in provoking the movement of mucus mouthward, which then leads to expectoration of sputum. King et al (15) and Warwick and Hansen (51) propose that HFCC is an excellent alternative to standard chest physiotherapy.

\section{Surfactants}

The principal biological function of pulmonary surfactants is to keep the alveoli open during breathing. In the airways, surfactants can provide lubrication for cough clcatance. They also improve interaction with cilia, thercby facilitating ciliary beating. Hence, surlictants have the potential to improve both mucociliary and cough clearance, and to reduce surface tension and physical entinglements within the mucous gel (52).

Various studies have shown that the viscoclastic properties of airway mucus are altered by airway lipids (53-55). Sputum from CF patients demonstrates a correlation between changes in rheological properties and changes in phospholipid content (53). De Sanctis et al (52) reported no change in the viscoelasticity of dog tracheal mucus after administration of porcine surfactant (Curosurf, Chiesi, Parma, Italy), but a four- to sixfold increase was observed in mucus clearance, partially due to stimulation of ciliary beat frequency, and possibly due to changes in the surface properties of secretions and their interaction with the cilia. However, Festa et al (5.5) showed that direct application of bovine surfactant (bLES) to CF sputum reduced mucus rigidity and improved mucus clearability on the isolated frog palate.

Modification of the mucous bilayer (gel and sol) by exo genously applicd surfactants could improve mucociliary clearance by enhancing the sliding of the gel phase over the sol phase (56). It has been suggested that surlactants facilitate the formation of interfacial bilayers between the mucus and the periciliary fluid (57). Enhanced bilayer formation between the two airway fluid phases would serve to augment the transfer of kinctic energy between the cilia and the mu- 


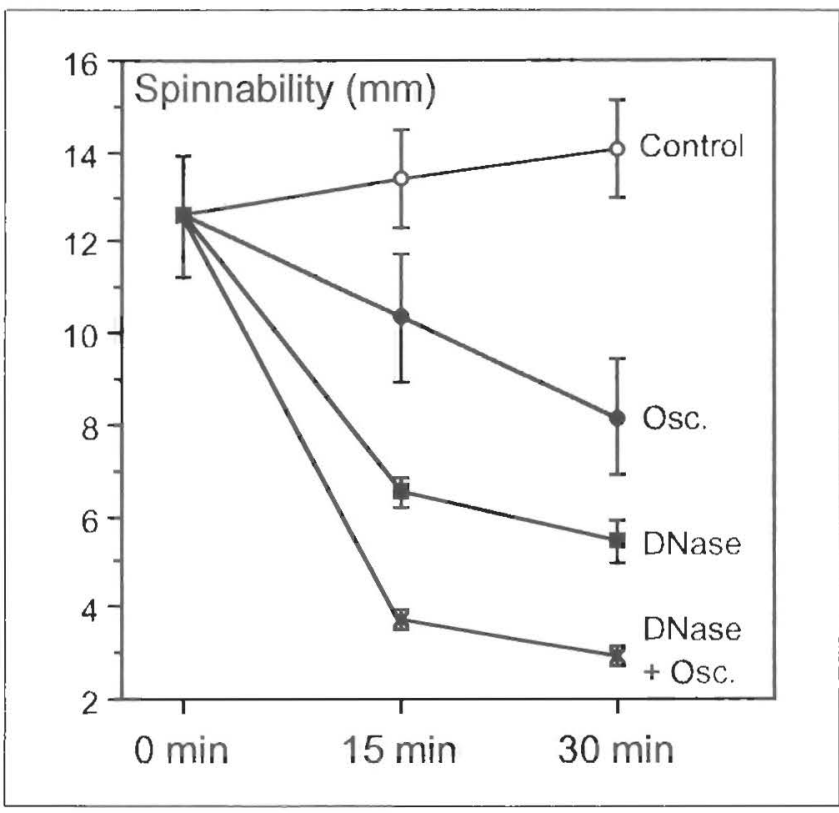

Figure 2) Combined effects of oscillation $(\mathrm{OSc})$ and recombinam human DNase on spinnability (mean $\pm S D$ ) of cystic fibrosis sputum. compared with effects of individual treatments and comtrol

cous layer by improving the no-slip condition necessary for efficient momentum transfer between the layers (58).

\section{COMBINED TREATMENTS WITH MUCOTROPIC AGENTS}

As shown above, treatments with a variety of individual mucotropic agents have successfully improved the properties of mucus, leading to increased mucous clearance. However, a combination of mucotropic approaches may produce even greater effects upon mucolysis, as illustrated by the possibilities in Table 1. For example, both oscillation and the enzyme rhDNase can break apart the fragile DNA molecules found in CF sputum. Although the independent results of studies of high frequency oscillation (51) and rhDNase (42) are very encouraging, these two therapies have not been researched to determine their additive effect on mucus clearance in CF patients. Results from in vitro studies of the individual and combined effects of uscillation, saline and rhDNase on the spinnability of CF sputum $(16,59)$ (Figure 2) indicated that additive treatment with rhDNase and oscillation decreases spinnability of CF sputum significantly more than with either treatment alone (eg, saline alone or oscillation alone) $(\mathrm{P}<0.01)$.

As another example, hoth rhDNase and gelsolin are involved in breaking up the excess crosslinks resulting from infection byproducts released into the mucus. Gelsolin, which binds to monomeric actin, is a protein capable of shortening the length of actin filaments (45), analogous to the action by rhDNase on DNA. In an in vitro study, Vasconcellos et al (47) combined these two mucotropic agents and reported that DNase may also reduce the viscosity of $\mathrm{CF}$ sputum through its action as an actin-binding protein (45). Actin also inhibits the DNA-hydrolyzing activity of rhDNase
$(60)$; therefore, by binding actin, the action of rhDNase in CF sputum may be enhanced. By reducing the length of actin filaments, gelsolin has been shown to reduce viscoelasticity of CF sputum in vitro (47). Additionally, a recent in vitro study (49) showed that combined treatment with gelsolin and rhDNase was more effective in reducing the viscoelasticity of CF sputum than individual treatments with either agent alone, indicating synergy between gelsolin and rhDNase.

As shown above, these in vitro results $(16,47,49)$ demonstrate an incremental or optimal effect from the additive effects of mucotropic agents. This may suggest potential superiority of combinations of chemical (eg, rhDNase) and physical (eg, oscillation) treatments on CF patients. Further studies are required to confirm these findings, to assess mucus clearability directly and to extend the observations, not only to a larger number of CF patients, but also to paltients with other types of pulmonary diseases.

\section{SUMMARY}

Airway mucus has a number of functions within the human body. In proper balance, airway mucus is generally beneficial in its effects to humans. The advantage of airway mucus is that it serves as a protective layer, trapping bacteria, viruses and foreign bodies in the conducting airways of the respiratory tract. The primary drawback is that the accumulation of airway mucus blocks the small airways, causing airway obstruction. People suffering from diseases characterized by mucus hypersecretion (eg, chronic bronchitis, CF) have excess mucus obstructing their airways and will benefit from measures designed to enhance its rate of elimination.

A variety of mucotropic modalities are involved in reducing the viscoelasticity and improving the clearability of the mucous gel. Previous in vitro and in vivo studies, using individual mucotropic agents $(42,51)$, have been successful, and a few studies, including ours $(16,49)$, indicate that combined mucolytic treatments have greater potential. Nevertheless, additional studies are required to confirm these findings and to define further the additive effects of mucolysis with combined treatments of physical and biochemical muco. tropic agents.

ACKNOWLEDGEMENTS: This paper was adapted in part from the MSc thesis of B Dasgupta. The authors thank Drs A Dean Befus, Marek Duszyk, Neil E Brown and Bruce K Rubin for their critical review of the original manuscript. B Dasgupta was supported by studentship awards from the Alberta Lung Association and the Canadian Cystic Fibrosis Foundation.

\section{REFERENCES}

1. Boat TF, Cheng PW, Iyer RN, Carlson DM, Polony I. Human respiratory tract secretions: mucous glycoproteins of nonpurulent tracheobronchial secretions, and sputum of patients with bronchitis and cystic fibrosis. Arch Biochem Biophys 1976; 177:95-104.

2. Litt M, Khan MA, Chakrin LW, Wardell JR, Christian P. The viscoelasticity of fractionated canine tracheal mucus. Biorheology 1974;11:111-7.

3. Roussel P, Degand P, Lamblin G, Laine A, Lafïte JJ. Biochemical definition of human tracheobronchial mucus. Lung 1978;154:241-60. 
4. Hilding AC. Experimental studies on some little understood aspects of the physiology of the respiratory tract and their clinical importance. Trans Am Acad Opthalmal Otolaryngol 1961;65:475-95.

5. Sanderson MJ, Sicigh MA. Ciliary activity of cultured rabbit tracheal epithelium: beat pattern and metachrony. J Cell Sci 1981;47:331-47.

6. Silberberg A, Meyer FA. Structure and function of mucus. In: Chantler EN, Elder JB, Elstein M, eds. Mucus in Health and Disease II. New York: Plenum Press, 1982:53-74.

7. Lofdahl CG, Odeblad E. Biophysical variables relating to viscoelastic properties of mucus secretions, with special reference to NMR-methods for viscosity. In: Berglund $\mathrm{E}$, Nilsson BS, Mossberg B, Bake B, eds. Workshop on Cough and Expectoration. 1979:120-1.

8. Lifsitz MI, Denning CR. Quantitative interaction of water and cystic fibrosis. Am Rev Respir Dis 1970;102:456-8.

9. Picot R, Das I, Reid L. Pus, deoxyribonucleic acid, and sputum viscosity. Thorax 1978;33:235-42.

10. List SJ, Findlay BP, Forstner GG, Forstner JF. Enhancement of the viscosity of mucin by serum albumin. Biochem $J$ 1978;175:565-71.

11. Litt M, Khan MA, Chakrin LW, Sosnowski G, Wardell JR Jr. Effect of chronic sulfur dioxide inhalation on rheological properties of tracheal mucus. Biorheology 1976;13:107-14.

12. King M. Mucus, mucociliary clearance and coughing. In: Bates DV, ed. Respiratory Function in Disease, 3rd edn. Philadelphia: Saunders, 1989:69-78.

13. Puchelle E, Zahm JM, Polu JM, Sadoul P. Drug effects on viscoelasticity of mucus. Eur J Respir Dis 1980;61:195-208.

14. Rubin BK, MacLeod PM, Sturgess J, King M. Recurrent respiratory infections in a child with fucosidosis: is the mucus too thin for effective transport? Pediatr Pulmonol $1991 ; 10: 304-9$

15. King M, Phillips DM, Gross D, Vartian V, Chang HK, Zidulka A. Enhanced tracheal mucus clearance with high frequency chest wall compression. Am Rev Respir Dis 1983;128:511-5.

16. Dasgupta B, Tomkiewicz RP, Boyd WA, Brown NE, King M. Effects of combined treatment with rhDNase and airflow oscillations on spinnability of cystic fibrosis sputum in vitro. Pediatr Pulmonol 1995. (In press)

17. Ventresca GP, Cicchetti, Ferrari V. Acetylcysteine. In: Braga PC, Allegra L, eds. Drugs in Bronchial Mucology. New York: Raven Press, 1989:77-102.

18. Roberts GP. The role of disulfide bonds in maintaining the gel structure of bronchial mucus. Arch Biochem Biophys 1976;173:528-37.

19. Davis SS, Deverell LC. The effect of stilfhydryl compounds and cross-linking agents on the viscous and viscoelastic properties of mucus. Biorheology 1975;12:225-32.

20. Sheffner AL. The reduction in vitro in viscosity of mucoprotein solutions by a new mucolytic agent, $\mathrm{N}$-acetyl-L-cysteine. Ann NY Acad Sci 1963;106:298-310.

21. Martin R, Litt M, Marriott C. The effect of mucolytic agents on the rheologic and transport properties of canine tracheal mucus. Am Rev Respir Dis 1980;121:495-500.

22. Lieberman J. Measurement of sputum viscosity in a cone-plate viscometer. Am Rev Respir Dis 1968;97:662-72.

23. Sheffner AL, Medler EM, Jacobs LW, Sarrett HP. The in vitro reduction in viscosity of human tracheobronchial secretions by acetylcysteine. Am Rev Respir Dis 1964;90:721-9.

24. Richardson PS. The principles of drug action on cough and on sputum characteristics. Eur J Respir Dis 1980;61:67-73.

25. Waldron-Edward D, Skoryna SC. The mucolytic activity of amides. A new approach to mucus dispersion. Can Med Assoc J 1966;94:1249-56.

26. Dippy JE, Davis SS. Rheological assessment of mucolytic agents on sputum of chronic bronchitics. Thorax
1969:24:707-13.

27. Hirsch SR, Zastrow JE, Kory RC. Sputum liquefying agents: a comparative in vitro evaluation. J Lab Clin Med 1969;74:346-53.

28. Marriott C, Richards JH. The effects of storage and potassium iodide, urea, and N-acetyl-L-cysteine and Triton X-100 on the viscosity of bronchial mucus. Br J Dis Chest 1974;68:171-82.

29. Ziment I. Hypertonic solutions, urea, and ascorbic acid. In: Braga PC \& Allegra L, eds. Drugs in Bronchial Mucology. New York: Raven Press, 1989:137-143.

30. Ziment I. Respiratory Pharmacology and Therapeutics. Philadelphia: WB Saunders, 1978:60-104.

31. Lieberman J, Kurnick NB. Influence of deoxyribonucleic acid content on the proteolysis of sputum and pus. Nature 1962; 196:988-90.

32. Lieberman J. Inhibition of protease activity in purulent sputum by DNA. J Lab Clin Med 1967;70:595-605.

33. Pavia D, Thompson DL, Clarke SW. Enhanced clearance of secretions from the human lung after the administration of hypertonic saline aerosol. Am Rev Respir Dis 1978;117:199-203.

34. Wanner A. Clinical aspects of mucociliary transport. Am Rev Respir Dis 1977;116:73-125.

35. Wanner A. Pulmonary defence mechanisms: mucociliary clearance. In: Simmons DH, ed. Current Pulmonology. Chicago: Year Book Medical Publisher, 1980:270-82.

36. Robinson M, King M, Tomkiewicz RP, et al. Effect of hypertonic saline, amiloride and cough on mucociliary clearance in patients with cystic fibrosis. Am J Respir Crit Care Med 1994;149:A669. (Abst)

37. Reidler J, Reade T, Button B, Robertson CF. A pilot study of inhaled hypertonic saline to increase sputum production in adolescents with cystic fibrosis. Eur Respir J 1994;7:429s. (Abst)

38. Shak S, Capon DJ, Hellmiss R, Marstars SA, Baker CL. Recombinant human DNase I reduces the sputum viscosity of cystic fibrosis sputum. Proc Natl Acad Sci USA 1990;87:9188-92.

39. Lethem MI, James SL, Marriott C, Burke JF. The origin of DNA associated with mucous glycoproteins in cystic fibrosis sputum. Eur Respir J 1990;3:19-23.

40. Zahm JM, Girod de Bentzmann S, Deneuville E, et al. Dose-dependent in vitro effect of recombinant human DNase on rheological and transport properties of cystic fibrosis respiratory mucus. Eur Respir J 1995;8:381-6.

41. Ranasinha C, Assoufi B, Shak S, et al. Efficacy and safety of short-term administration of aerosolized recombinant human DNase I in adults with stable stage cystic fibrosis. Lancet 1993;342:199-202.

42. Fuchs HJ, Borowitz DS, Christiansen DH, et al. Effect of aerosolized recombinant human DNase on exacerbations of respiratory symptoms and on pulmonary function in patients with cystic fibrosis. N Engl J Med 1994;331:637-48.

4.3. Shah PL, Ingham S, Marriott C, Scott SF, Hodson ME. The in vitro effects of two novel drugs on the rheology of cystic fibrosis and bronchiectasis sputum. Eur Respir J 1994;7: I 2s. (Abst)

44. Fick RB, Anzueto A, Mahutte K. Recombinant DNase mortality reduction in acute exacerbations of chronic bronchitis. Clin Res 1994;42:294A. (Abst)

45. Stossel TP. The mechanical responses of white blood cells. In: Gallin GI, Goldstein I, Snyderman R, eds. Inflammation. Basic Principles and Clinical Correlates, 2nd edn. New York: Raven Press, 1992:459-75.

46. Mornet D, Ue K. Proteolysis and structure of skeletal muscle actin. Proc Natl Acad Sci USA 1984;81:3680-4.

47. Vasconcellos CA, Allen PG, Wohl M, Drazen JM, Janmey PA. Reduction in sputum viscosity of cystic fibrosis sputum in vitro 
by gelsolin. Science 1994;263:969-7 I .

48. Tomkiewicz RP, De Sanctis GT, Fisher R, Rubin BK, Drazen JM, King M. Effects of the actin filament severing protein, gelsolin on cystic fibrosis sputum viscoelasticity in vitro. Pediatr Pulmonol 1994; 10(Suppl):242. (Abst)

49. Dasgupta B, Tomkiewicz RP, De Sanctis GT, Boyd WA, King M. Mucolytic synergism in cystic fibrosis (CF) sputum with combined rhDNase and gelsolin treatment. Am J Respir Crit Care Med 1995;151:A19. (Abst)

50. Tomkiewič RP, Biviji AA, King M. Effects of oscillatling air flow on rhcological properties and clearability of mucous gel simulants. Biorheology 1994;31:511-20.

51. Warwick WJ, Hansen LG. The long-term effect of high frequency chest compression therapy on pulmonary complications of cystic fibrosis. Pediatr Pulmonol 1991:11:265-71

52. De Sanctis GT, Tomkiewic, RP, Rubin BK, Schürch S, King M. Exogenous surfactant cnhances mucociliary clearance in the anesthetized dog. Eur Respir J 1994;7:1616-21.

53. Galabert C. Jacquol J, Zahm JM, Puchelle E. Relationship between lipid content and the rheological properties of airway secretions in cystic fibrosis. Clin Chim Acta 1987;164:139-49.

54. Rubin BK. Ramirez O, King M. The role of mucus rheology and transport in neonatal respiratory distress syndrome and the effect of surfactant therapy. Chest 1992;101:1080-5.

55. Festa E, Saldiva PHN, King M. Effects of bovine surfactant (bLES) on rheological properties and mucociliary transport of respiratory secretions in cystic fibrosis (CF) patients. Am . I Respir Crit Care Med 1995;151:A314. (Abst)

56. King M, Rubin BK. Rheology of airway mucus: relationship) with clearance function. In: Takishima $T$, Shimura $S$, ecis. Airway Secretion: Physiological Bases for the Control of Mucous Hypersecretion. New York: Marcel Dekker. 1994:283-314.

57. Schürch S, Gehr P, Im Hof V, Geiser M, Green F. Surfactant displaces particles towards the epithelium in airways and alveoli. Respir Physiol 1990;80:17-32.

58. King M, Agarwal M, Shukla JB. A planar model for mucociliary transport: Effect of mucus viscoelasticity. Biorheology 1993;30:49-61.

59. Dasgupta B, Tomkiewicz RP, Boyd WA, Brown NE, King M. Combined effects of oscillation, and rhDNase on spinnability of cystic fibrosis sputum. Pediatr Pulmonol 1994;10(Suppl):266. (Abst)

60. Hitchock SE, Carlsson L, Lindberg U. Depolymerization of F-actin by deoxyribonuclease I. Cell 1976;7:531-42. 


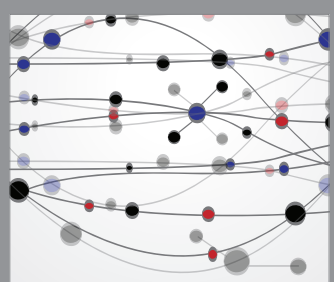

The Scientific World Journal
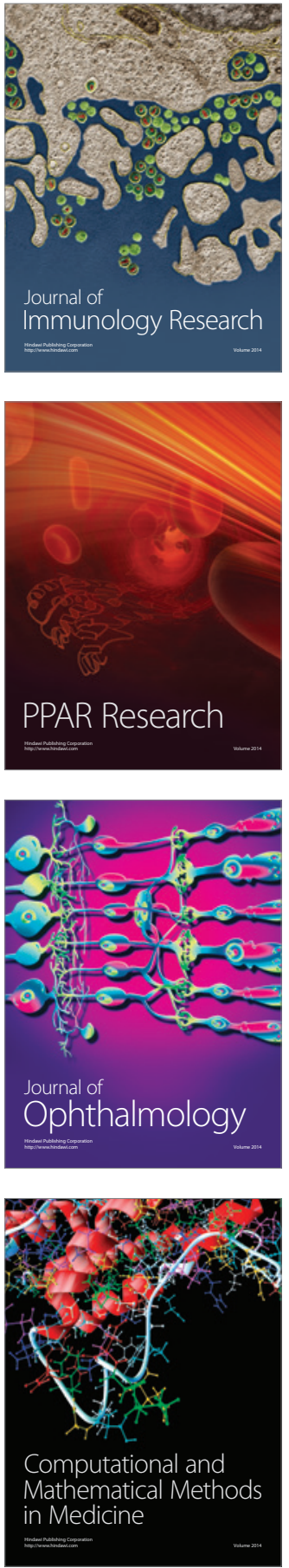

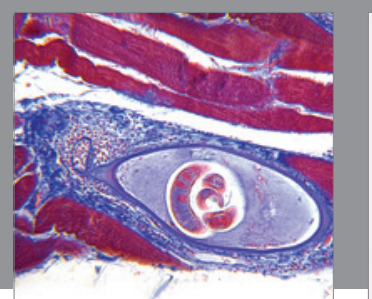

Gastroenterology Research and Practice

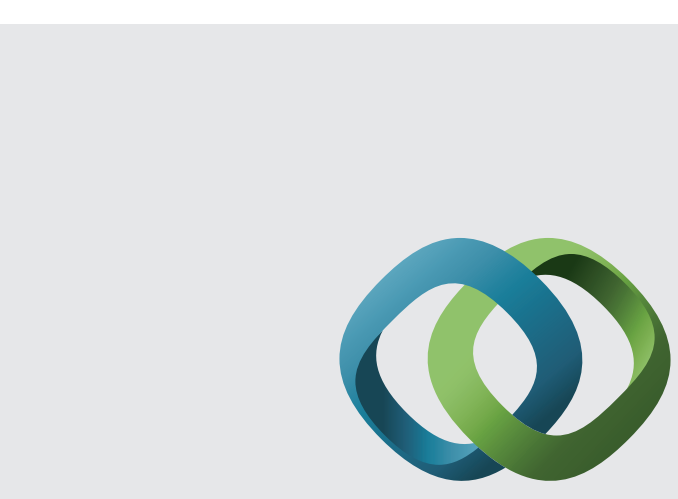

\section{Hindawi}

Submit your manuscripts at

http://www.hindawi.com
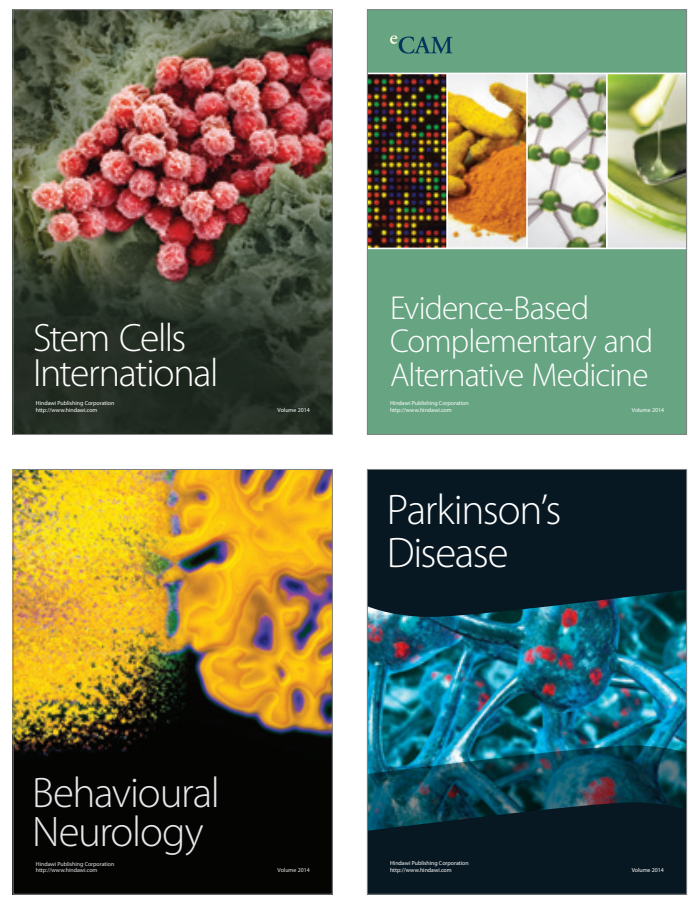
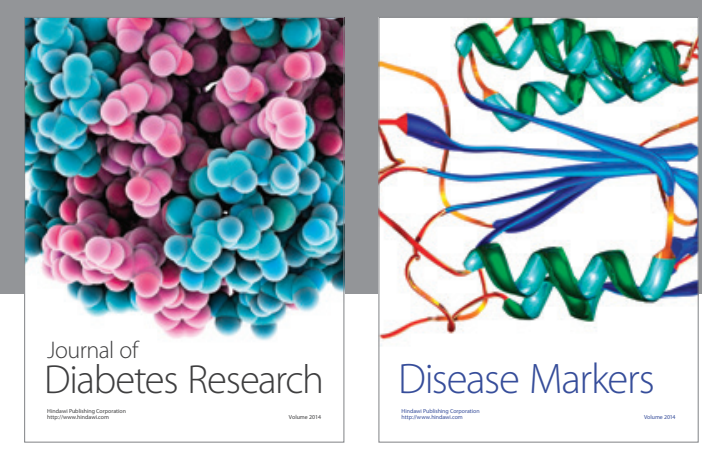

Disease Markers
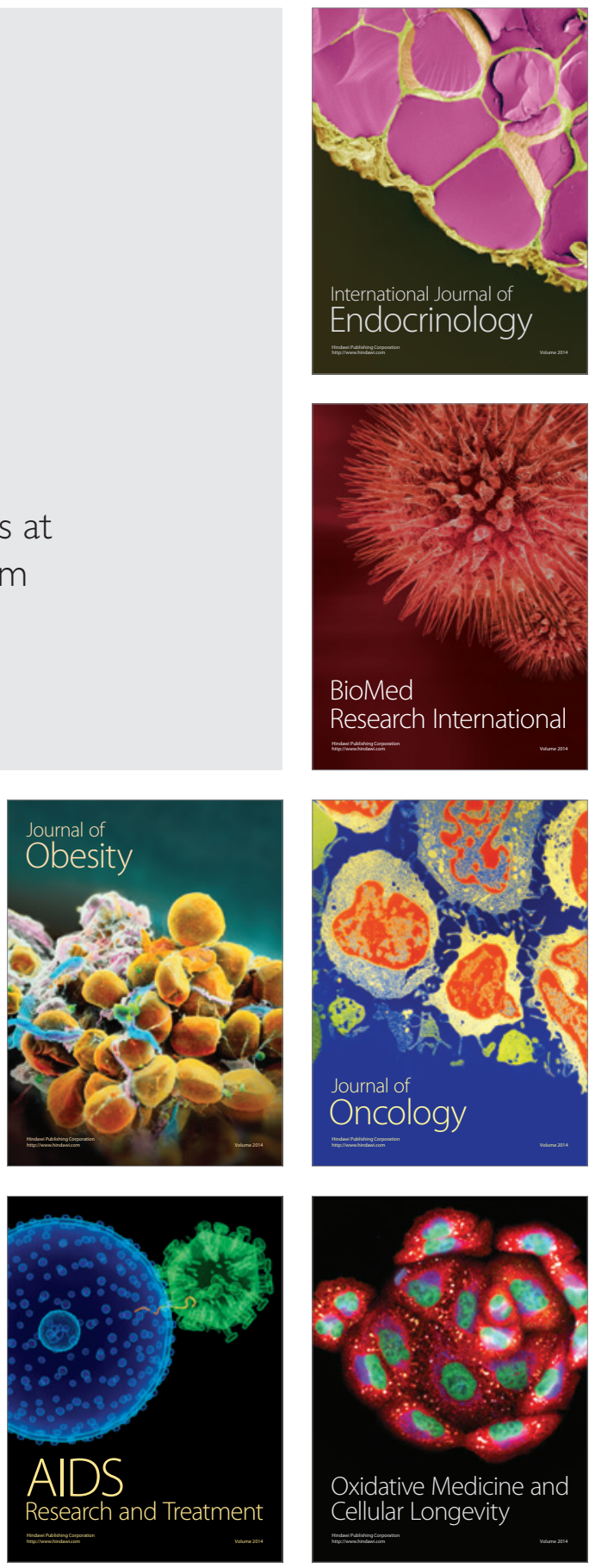